\title{
Socioeconomic Impacts of Leishmaniases on Households of Marigat Sub County, Baringo County of Kenya
}

\author{
Eric Gisege Okindo*, Sichangi Kasili, Helen Lydiah Kutima I, Joseph Mutai M
}

Jomo Kenyatta University of Agriculture and Technology, Kenya

*Corresponding author: Okindo EG, Jomo Kenyatta University of Agriculture and Technology, Kenya, Tel: +254 722677510; E-mail: ericokindo@yahoo.com

Received date: November 10, 2016; Accepted date: November 19, 2016; Published date: November 30, 2016

Copyright: ( 2016 Okindo EG, et al. This is an open-access article distributed under the terms of the Creative Commons Attribution License, which permits unrestricted use, distribution, and reproduction in any medium, provided the original author and source are credited.

\begin{abstract}
The global burden of leishmaniases has remained stable for some years, causing a morbidity and mortality mainly to the poor proportion of the population. An estimated 5 million people are at risk of infection in Kenya with 4,000 cases occurring annually. Despite these prevailing statistics, the socioeconomic costs to the leishmaniases are not known.
\end{abstract}

A cross-sectional study, which employed administration of structured questionnaires, was carried out in Marigat Sub County of Baringo County in 2015. Household heads were randomly selected whereas participants of focused group discussions (FGDs) were selected by purposive sampling. Data was analyzed by Chi-square test using SPSS version 20 software.

The study recruited 390 respondents, $53 \%$ and $48 \%$ females and males respectively. The majority (29\%) of respondents were illiterate. Whereas $44 \%$ had normal monthly expenditure of US\$10.01-50, the mean total expenditure due to visceral leishmaniasis (VL) was US $\$ 259.83$ per household with $50.26 \%$ using over US\$200.The mean number of economic days lost was 178 days. $9.1 \%$ of the respondents reported isolation of VL patients.

The cost of treating a patient with VL was way above the monthly expenditure of residents resulting in sinking the affected families in poverty. Days lost in the course of patient treatment of leishmaniasis could be used to improve livelihoods. There is need for interventions to increase access to affordable leishmaniases prevention, diagnosis and treatment. Poverty alleviation programmes should also be increased in Marigat Sub County and neighboring communities.

Keywords: Leishmaniases; Economic impacts; Social impacts; Baringo County

\section{Introduction}

Leishmaniases are protozoan infections caused by Leishmania $s p$. They are transmitted to humans by infected female sand flies of the genera Phlebotomus and Lutzomyia. Globally, 350 million people are at risk of infection, an estimated 14 million people are infected and each year about two million new cases occur [1]. The global burden of leishmaniases has remained stable for some years, causing a morbidity and mortality loss of 2.4 million disability adjusted life-years (DALYs) and approximately 70,000 deaths [2].

Visceral Leishmaniasis (VL) is endemic in arid and semi-arid regions of Kenya including the former Rift Valley and Eastern regions with small foci in North Eastern Kenya counties. It is estimated that about 4,000 cases occur annually in Kenya with 5 million people are at risk of infection [3]. The disease mainly affects children above two years and young adults but older people are also occasionally infected [4]. Visceral leishmaniasis ranges from asymptomatic infection to severe life-threatening infection [5]. The most common symptoms of VL include prolonged fever, weight loss, substantial swelling of the liver and spleen, darkening of the skin and anaemia [6]. It is a systemic disease, most severe form of leishmaniases infections and is usually fatal within two years if left untreated [5].
Cutaneous leishmaniasis is also endemic in Kenya. Of the 22 counties where leishmaniases are endemic in Kenya [3], Baringo County is the only foci where both VL and Cutaneous leishmaniasis (CL) are known to occur in Kenya [7]. Although the morbidity associated with CL is not significant, and the disease is not lethal, the disfigurement and resulting social stigmatization may cause or precipitate psychological disorders, along with restricting social participation of the individuals affected by the disease [8]. Some these manifestations remain lifelong. Their true burden remains largely invisible because the most affected live in remote areas and partly because the social stigma from deformities and disfiguring scars keeps patients hidden [1].

Costs associated with the treatment of leishmaniases range from direct costs of diagnosis, treatment, hospitalization and drugs administration, and indirect costs of transport, loss of days of productive life years and loss of profitable time of family members who take care of the patients $[9,10]$. Most often, families sell their assets or take loans with heavy interest to pay for leishmaniasis treatment [11]. In Kenya, these costs are not documented yet they can serve as an indicator for the policy makers and donors to realize the burden of the disease on the people already burdened with poverty [9]. Additionally, literature on social impacts of leishmaniases, especially CL, is scanty.

The current study was therefore carried out in to determine the social-economic costs of leishmaniases in Marigat Sub County, Baringo County of Kenya. 
Citation: Eric Gisege Okindo*, Sichangi Kasili, Helen Lydiah Kutima I, Joseph Mutai M (2016) Socioeconomic Impacts of Leishmaniases on Households of Marigat Sub County, Baringo County of Kenya. J Trop Dis 4: 226. doi:10.4172/2329-891X.1000226

Page 2 of 5

\section{Materials and Methods}

Study site: The study was carried out in Marigat Sub County, in Baringo County between September and November of 2015. With an area of $11,075.3 \mathrm{~km}^{2}$, Baringo County has a population of 555,561 . Marigat Sub County is one of the densely populated areas in Baringo County. It is a semi-arid area situated at the altitude of 1067 metres above sea level and is approximately $250 \mathrm{~km}$ west of Nairobi City County. The area has a mean temperature of about $32.8^{\circ} \mathrm{C} \pm 1.6^{\circ} \mathrm{C}$ with total amount of annual rainfall of $512 \mathrm{~mm}$ occurring in two seasons: March to August and November to December. Farming, mainly in irrigated ares, is the major income generating activity. The remainder of the county is mainly rangelands with the rearing of goats, sheep, cattle and camels and bee keeping forming the major livestock activities. Baringo County has 89 health facilities distributed all over the County. Most of them are under utilized due to lack of staff and equipment. The average distance to the nearest health facility is $15 \mathrm{~km}$.

Design: This was a cross-sectional study that employed both quantitative and qualitative methods of data collection. Tables of random numbers generated from the local chiefs' records were used to select the target population. The target population comprised of household heads either the fathers or mothers or any adult person in charge (aged 18 years and above) of the household. Study participants had to voluntarily consent, resident of Marigat Sub County for at least one year and had had one of the family member or themselves affected with leishmaniases. Purposive sampling was used to select opinion leaders, community health extension workers (CHEWs), administrative local chiefs and divisional health officers for focus group discussions.

Data collection: Data collection techniques included use of focus group discussions and the administration of structured questionnaires. The quantitative techniques consisted of household surveys using questionnaires with both closed and open-ended questions. Closed questions were used to obtain demographic characteristics. Only household heads were interviewed. Trained research assistants helped in questionnaire administration and moderation because of their fluency in the local language. Qualitative data were obtained using focus group discussions (FGDs). The FGDs per location was conducted with the opinion leaders including two church leaders, two village elders, two sub chiefs and two CHEWs. The FGDs were of mixed gender and each had 6-12 participants. The FGDs were moderated by two trained interviewers as shown in Figure 1. Discussion themes included perceptions of the problem of leishmaniases in the community, social impacts of leishmaniases, attitude and practices associated with the disease. Sampled respondents signed consent forms written in the language they understood best in the presence of a church leader or village elder as a witness.

Data analysis: Data from the questionnaire was entered in Ms Excel spread sheet and exported to SPSS (version 20.0) software for analysis. Chi-square test was used to establish the association between the dependent and independent variables.

Ethical approval: The approval to carry on with the research was given by Kenyatta National Hospital/University of Nairobi ethical review committee (KNH/UON-ERC).

\section{Results}

The study recruited 390 respondents of which $53 \%$ were female sand $48 \%$ males. In terms of marital status, $64 \%$ were married, $16 \%$ were widowed, $11 \%$ were single and $9 \%$ were divorced. Table 1 shows occupation and education level of household heads in Marigat Sub County.

\begin{tabular}{|l|l|l|}
\hline Characteristic & $\mathbf{n}$ & $\mathbf{n} \%$ \\
\hline Occupation & & \\
\hline Farmers & 306 & 78.5 \\
\hline Teachers & 12 & 3.1 \\
\hline Health Workers & 7 & 1.8 \\
\hline Others & 60 & 15.4 \\
\hline Education level & & \\
\hline Not educated & 114 & 29.1 \\
\hline Primary not completed & 106 & 27 \\
\hline Primary completed & 96 & 24.5 \\
\hline Secondary education & 62 & 15.8 \\
\hline Post-secondary education & 12 & 3.1 \\
\hline
\end{tabular}

Table 1: Occupation and education level of household heads in Marigat Sub County.

The number of farmers was significantly higher than that of any other occupation $(\mathrm{P}<0.05)$.

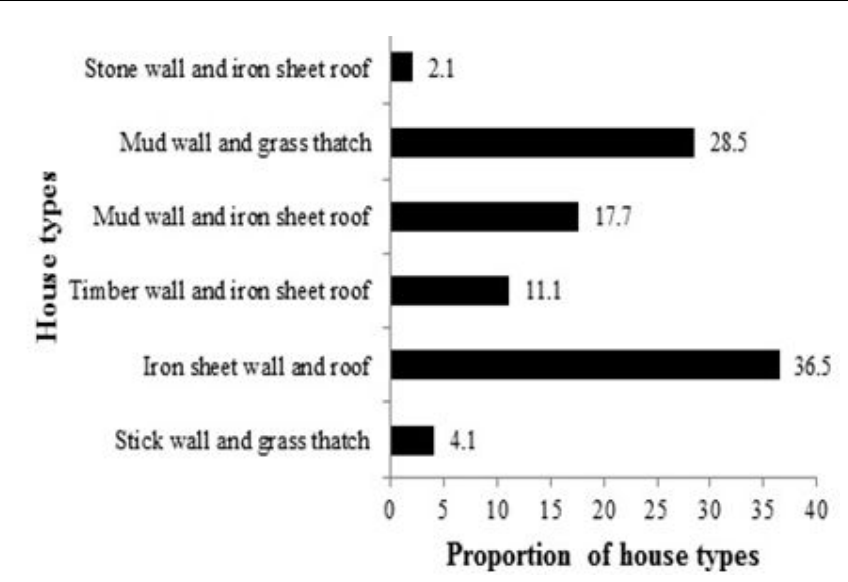

Figure 1: Shows house type distribution in Marigat Sub County. Iron sheet walled and roofed houses were the majority though not significantly different from the other house types in proportion $(\mathrm{P}>0.05)$.

The highest proportion (29\%) of household heads did not receive even basic education though not significantly different from other levels of attained education $(\mathrm{P}>0.05)$. Leishmaniases make the situation even worse by sinking most of the house hold into extreme poverty since management of leishmaniases can be catastrophic to the households (Figure 2). 
Citation: Eric Gisege Okindo*, Sichangi Kasili, Helen Lydiah Kutima I, Joseph Mutai M (2016) Socioeconomic Impacts of Leishmaniases on Households of Marigat Sub County, Baringo County of Kenya. J Trop Dis 4: 226. doi:10.4172/2329-891X.1000226

Page 3 of 5

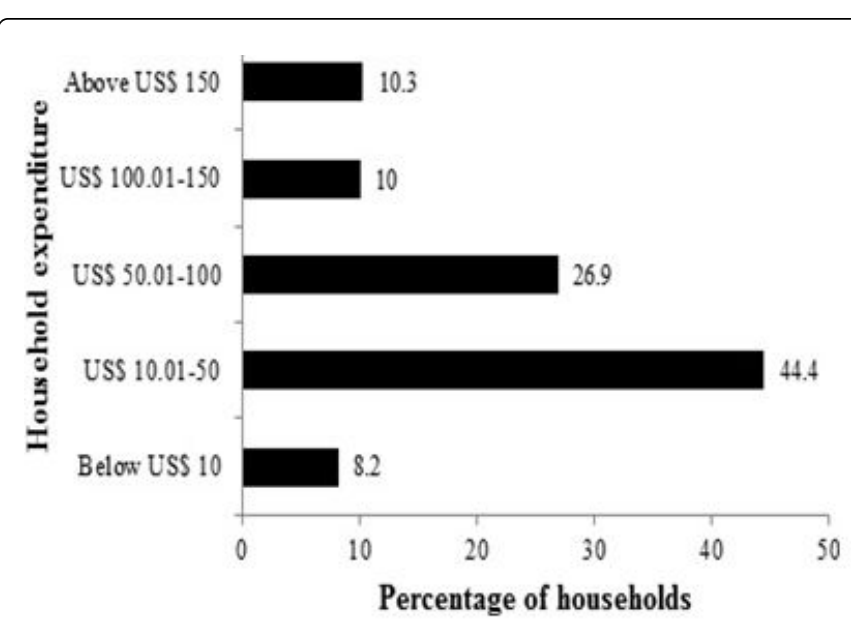

Figure 2: Shows normal monthly household expenditure of Marigat Sub County members. The proportion of persons with US\$ 10.01-50 normal expenditure was the highest. Persons with normal monthly expenditure above US\$ 100 were significantly lower than those whose expenditure was less than US\$ $50(\mathrm{P}<0.05)$.

Table 2 shows expenses associated with hospital treatment of leishmaniasis infected family members.

The grand mean total expenditure by respondents due to leishmaniasis in Marigat Sub County was Kenyan Shillings 25,983.77 (\$259.83) per household.

\begin{tabular}{|c|c|c|c|}
\hline Variable & Mean & Minimum & Maximum \\
\hline Drug costs from hospital & $\begin{array}{l}11116.30(U \\
S \$ 111.16)\end{array}$ & $50($ US $\$ 0.5)$ & $\begin{array}{l}60000(\text { US } \\
\$ 600)\end{array}$ \\
\hline $\begin{array}{l}\text { Costs of drugs from chemists } \\
\text { outside the Hospital }\end{array}$ & $\begin{array}{l}5299.54(\text { US } \\
\$ 54)\end{array}$ & $80($ US $\$ 0.8)$ & $\begin{array}{l}60000 \quad(\text { US } \\
\$ 600)\end{array}$ \\
\hline Costs of laboratory Tests & $\begin{array}{l}1730.33(\text { US } \\
\$ 17.30)\end{array}$ & $50($ US $\$ 0.5)$ & $\begin{array}{l}23000(\text { US } \\
\$ 230)\end{array}$ \\
\hline Costs of hospital consultation & $\begin{array}{l}583.90(\text { US } \$ \\
5.84)\end{array}$ & 0 & $\begin{array}{l}\text { 12000(US } \\
\$ 120)\end{array}$ \\
\hline Costs of hiring a vehicle & $\begin{array}{l}3235.51(\text { US } \\
\$ 32.36)\end{array}$ & 0 & $\begin{array}{l}50000(\text { US } \\
\$ 500)\end{array}$ \\
\hline Costs of Public Transport & $\begin{array}{l}1758.21(\text { US } \\
\$ 17.58)\end{array}$ & 0 & $\begin{array}{l}50000(\text { US } \\
\$ 500)\end{array}$ \\
\hline $\begin{array}{l}\text { Total cost of travelling to the } \\
\text { hospital by caretaker }\end{array}$ & $\begin{array}{l}3761.49(\text { US } \\
\$ 37.61)\end{array}$ & $80($ US $\$ 0.8)$ & $\begin{array}{l}20000 \text { (US } \\
\$ 200)\end{array}$ \\
\hline $\begin{array}{l}\text { Money used by the caretaker to buy } \\
\text { food in the hospital }\end{array}$ & $\begin{array}{l}3568.50(\text { US } \\
\$ 35.69)\end{array}$ & 7(US\$0.07) & $\begin{array}{l}25000 \text { (US } \\
\$ 250)\end{array}$ \\
\hline $\begin{array}{l}\text { Costs of buying food for the sick } \\
\text { before recovery at home }\end{array}$ & $\begin{array}{l}4,929.99 \text { (US } \\
\$ 49.30)\end{array}$ & $\begin{array}{l}15(\text { US } \\
\$ 0.07)\end{array}$ & $\begin{array}{l}30,000 \text { (US } \\
\$ 300)\end{array}$ \\
\hline
\end{tabular}

Table 2: Monetary household expenditure associated leishmaniases treatment in Marigat Sub County.

Table 3 shows the number of days lost in case a family member contracts leishmaniasis. The mean number of economic days lost was 178 days.

\begin{tabular}{|l|l|l|l|}
\hline Variable & Mean & Minimum & Maximum \\
\hline $\begin{array}{l}\text { Number of days the caretaker } \\
\text { visited the patient in the hospital }\end{array}$ & 24 & 0 & 100 \\
\hline $\begin{array}{l}\text { Number of days the patient was } \\
\text { taken care of until stable }\end{array}$ & 41 & 2 & 360 \\
\hline $\begin{array}{l}\text { Number of days the patient was } \\
\text { unable to carry out their normal } \\
\text { duties }\end{array}$ & 70 & 7 & 630 \\
\hline $\begin{array}{l}\text { Number of days the caretaker was } \\
\text { unable to carry out their normal } \\
\text { duties }\end{array}$ & 43 & 2 & 365 \\
\hline
\end{tabular}

Table 3: Number of days spent on leishmaniasis treatment in Marigat Sub County.

A quarter of the respondents $(25.6 \%)$ indicated that stigma and discrimination were associated with leishmaniases. The number of respondents reporting leishmaniases patients stigmatization and discrimination was significantly higher than those who did not $(\chi=$ 12.908, df $=1, \mathrm{P}<0.001)$.

\section{Discussion}

Majority of households' expenditure per month was between Kenya Shillings 1001-5000 (US \$10-50). This income expenditure is less than a dollar per day. On the other hand, the current study showed that mean total direct medical expenditure due to Kala azar in Marigat Sub County was Kshs 25983.77 (US\$259) per patient. This is way up the affordability of most of the residents. The estimate of the costs incurred by the household per each case of leishmaniases was higher than the estimates given by other researchers which vary from US $\$ 113.60$ to US $\$ 232.10[12,13]$. The high costs in Kenya are as a result of high transport costs used due to the long distances covered to the hospital by patients and their caretakers for treatment. Also being semi arid area, the costs of foods for special diet required by the patient during recuperation is the high. Leishmaniases make the situation even worse by sinking most of the house hold into extreme poverty since management of leishmaniases can be catastrophic to the households [13]. Studies have shown that leishmaniases are neglected tropical diseases that have strong but complex links with poverty [14]. Leishmaniases also affect disproportionately the poorest segments of rural populations in southern Asia, eastern Africa and Brazil [15]. As a consequence of this high cost of leishmaniases treatment, some people in Marigat tend to consult the cheaper traditional healers. Since farmers in Marigat Sub County form the largest group in terms of occupation, the activity could be used to change this poverty pattern. Even though, meaningful farming is practiced only in small part of the Sub County that is supplied with irrigation water. To further complicate the situation, most of houses in Marigat were made of stick or iron sheet walls with open eaves, this simplicity being occasioned by poverty. These housing structures and living conditions favour transmission of leishmaniases by sand flies. Infections predispose the affected persons again to poverty.

The impact of leishmaniases in a household is compounded by the difficulty in negotiating the medical system. Household members and leishmaniases patients described their difficulty in overcoming barriers to diagnosis and treatment at hospitals, including payments for diagnostic tests, treatment, injection equipment, and small payments to those who controlled access to care. Despite these difficulties, family 
members felt that accessing treatment was essential to avoid death $[15,16]$. The total cost of treating a leishmaniasis patient was five times more than what most households were spending monthly. The diseases therefore cause a huge financial burden to the affected households whenever they strike. In fact most households are forced to take loan with high interest rates or sell assets such as livestock to cover the costs of treatment. This pattern has also been observed in Bangladesh [17], and Nepal [18]. The greatest cost is the one of buying the drugs for treatment. The cost of drugs from the hospital was estimated at Kshs $11,116.30$ (US\$111.2). This estimate is slightly higher than the US $\$ 100$ reported in another study [9]. The cost of buying both therapeutic drugs and nutritive supplements from pharmaceutical stores outside the hospital was estimated at Kshs 5299.54 (US\$53). The cost of buying the drugs when they are out of stock in the hospital is almost three times higher than the official price. This was consistent with study carried out on economic impact of leishmaniasis in Bangladesh [17]. High drug prices are as a result of scant investment in the development of new drugs for leishmaniases hence the most effective treatments are often unavailable or unaffordable for patients in the endemic areas [15]. This is the reason why some governments where especially VL is endemic do subsidize drugs to make them affordable.

Studies show that people with leishmaniases may be ill for months while they are trying to rule out common diseases that are less expensive to treat [14]. They may also prioritize care within the household, generally seeking hospital care for children and men before adult women, who had significantly longer duration of illness than men [14]. Delays in appropriate leishmaniases diagnosis and treatment increase the risk of complications and death. They also augment the reservoir for further transmission. Adult women are particularly vulnerable to mortality and prolonged morbidity due to poorer underlying nutritional status from menstruation, childbearing and lactation, as well as treatment delays.

The grand mean number of economic days lost due to sickness by the patient and the caretaker was 178 days. The households of infected patient in Marigat Sub County were therefore incurring substantial costs to seek and receive medical treatment. Patients visit several health care providers where they pay for inefficient treatments thus subsequently depleting the little savings they have. When they are eventually diagnosed with leishmaniases for appropriate treatment, more time is spent on travelling to Kimalel health centre which is the widely known centre in Marigat for leishmaniases treatment. These days could otherwise be spent on income generating activities.

The current study shows that stigma and discrimination is associated to leishmaniases. The negative social impacts of leishmaniases have been observed in many studies. In Paras, respondents with the highest incidence of disease felt powerless in the face of dire emotional and economic consequences, and many equated the leishmaniases diagnosis with a death sentence [15]. Leishmaniases pose stigma, psychological stress and discrimination in the patients in the society [9]. Although the disease has been there for a long time, some people still believe in the discrimination of leishmaniases patients which is a negative setback. Isolation of patients may lead to psychological stress in the patients. There is need for the stakeholders to intervene and educate the community against this negative social practice of discriminating and stigmatizing patients. Knowledge, attitudes and practices studies on malaria suggest that education has a significant role to play in enhancing knowledge $[19,20]$. The low level education in most of the respondents in Marigat seems to negatively influence the fight against leishmaniasis patients' stigmatization and discrimination. It is documented for infectious diseases (eg: TB, malaria) that low levels of knowledge and awareness apparently influence initial health care seeking behavior after the onset of symptoms $[21,22]$.

\section{Conclusion}

Leishmaniases lead to enormous economic costs incurred in the course of treatment. The cost is higher than normal monthly expenditure of affected families. There are still negative social impacts such as stigma and discrimination on the infected individuals mainly because of the fear that it causes to the community. There is therefore need to improve access to affordable leishmaniases diagnosis and treatment in Marigat Sub County and neighboring communities through better coordination of available resources provided by the government and other organizations. Poverty alleviation programmes should be intensified and preferential especially in favour of the poorest in the community. Poverty can also be alleviated if water for consumption at home and irrigation and irrigation is made available. Many people are able to carry out small farming enterprises if water is available. Finally, promotion of anti-leishmaniases stigma and discrimination among the community members through education on transmission modes and treatment is necessary.

\section{Acknowledgements}

Authors wish to acknowledge community members of Marigat Sub County and most importantly the local chiefs, church leaders, household heads, Community Health Extension Workers and other persons who participated in the study.

\section{References}

1. WHO (2007) Department of Communicable Disease Surveillance and Response. WHO Report on global surveillance of epidemic-prone infectious diseases. Geneva.

2. Ngure P, Kimutai A, Tonui W, Ng'ang'a Z (2009) A review of Leishmaniasis in Eastern Africa. J Parasit Dis 4: 1-5.

3. Wasunna MK, Rashid JR, Mbui J, Kirigi G, Kinoti D, et al. (2005) A phase II Dose-Increasing study of sitamaquin for the treatment of Visceral Leishmaniasis in Kenya. Am J Trop Med Hyg 3: 871-876.

4. François C, Shyam S, Asrat H, Hashim G, Suman R, et al.(2007) Visceral leishmaniasis: what are the needs for diagnosis, treatment and control? Nat Rev Microbiol 5: 873-882.

5. Conjivaram V, Ruchir A (2007) Leishmaniasis. eMedicine journal.

6. WHO (2010) Control of the leishmaniases. Technical report series. Geneva.

7. Robert LL, Schaefer KU, Johnson RN (1994) Phlebotomine sandflies associated with households of human visceral leishmaniasis cases in Baringo District, Kenya. Ann Trop Med Parasitol 88: 649-657.

8. Kassi M, Kassi M, Afghan AK, Rehman R, Kasi PM (2008) Marring Leishmaniasis: The Stigmatization and the Impact of Cutaneous Leishmaniasis in Pakistan and Afghanistan. PLoS Negl Trop Dis 2: 259.

9. Boelaert M, Meheus F, Robays J, Lutumba P (2010) Socio economic aspects of neglected diseases: sleeping sickness and visceral leishmaniasis. Ann Trop Med Parasitol 104: 535-542.

10. Marinho DS, Casas CNPR, Pereira CC, Leite IC (2015) Health Economic Evaluations of Visceral Leishmaniasis Treatments: A Systematic Review. PLoS Negl Trop Dis 9: 0003527.

11. Okwor I, Uzonna J (2016) Social and Economic Burden of Human Leishmaniasis. Am J Trop Med Hyg 94: 489-493. 
Citation: Eric Gisege Okindo*, Sichangi Kasili, Helen Lydiah Kutima I, Joseph Mutai M (2016) Socioeconomic Impacts of Leishmaniases on Households of Marigat Sub County, Baringo County of Kenya. J Trop Dis 4: 226. doi:10.4172/2329-891X.1000226

Page 5 of 5

12. Rijal S, Koirala, P, Van S, Boelaert M (2005) The economic burden of visceral leishmaniasis for households in Nepal. Transactions Royal Soc Tropical Med \& Hyg 100: 838-884.

13. Adhikari SR, Maskay NM, Sharma BP (2009) Paying for hospital-based care of kala-azar in Nepal: assessing catastrophic, impoverishment and economic consequences. Health Policy Plan 24: 129-139.

14. Jorge A, Sergio Y, Caryn B (2006) Leishmaniasis and poverty. Trends Parasitol 22: 552-557.

15. Ahluwalia IB, Caryn B, Cristiane C, Tangin A, Rajib C, et al. (2003) Visceral leishmaniasis: consequences of a neglected disease in a Bangladeshi Community. Am J Trop Med Hyg 69: 624-628.

16. Kumar N, Siddiqui NA, Singh VP, Verma RB, Bhattacharya SK, et al. (2004) Grass-root level functionaries of kala-azar in Bihar. Chandigarh: Proceedings of the 31st Annual National Conference of Indian Association of Preventive and Social Medicine at PGIMER. Proceedings of the 31st Annual National Conference of Indian Association of Preventive and Social Medicine at PGIMER 41: 169-176.

17. Sharma A, Bern C, Varghese B (2006) The economic impact of visceral leishmaniasis on households in Bangladesh. Trop Med Int Health 11: 757-764
18. Rijal S, Koirala S, Van S (2006) The economic burden of visceral leishmaniasis for households in Nepal. Transactions Royal Soc Tropical Med \& Hyg 100: 838-841.

19. Panda R, Kanhekar LJ, Jain DC (2000) Knowledge, attitude and practice towards malaria in rural tribal communities of South Bastar district of Madhya Pradesh. J Commun Dis 32: 222-227.

20. Sharma AK, Aggarwal OP, Chaturvedi S, Bhasin SK (2003) Is education a determinant of knowledge about malaria among Indian tribal population? J Commun Dis 35: 109-117.

21. Enwuru CA, Idigbe EO, Ezeobi NV, Otegbeye AF (2002) Care-seeking behaviour patterns, awareness and diagnostic processes in patients with smear and culture- positive pulmonary tuberculosis in Lagos, Nigeria. Trans R Soc Trop Med Hyg 96: 614-616.

22. Matta S, Khokhar A, Sachdev TR (2004) Assessment of knowledge about malaria among patients reported with fever: a hospital-based study. J Vector Borne Dis 41: 27-31. 